\title{
ИНКЛЮЗИЯ И СЕЛЕКТИВНОСТЬ В КАТОЛИЧЕСКИХ ШКОЛАХ В ПОЛЬШЕ
}

Постсоциалистические трансформации сферы образования в странах Центральной и Восточной Европы имели различный характер. Если в России большинство учреждений среднего образования являются государственными, то в Польше начал формироваться сегмент частных школ. Негосударственные учебные заведения ориентированы на индивидуальные стратегии обучения. Наиболее типична такая стратегия для католических школ. Цель настоящей статьи - оценить инклюзивный потенциал польских католических школ. Материалы качественного социологического исследования, основанного на серии полуструктурированных интервью с директорами и учителями католических школ, позволяют описать как процедуры отбора учеников, так и способы интеграции нетипичных детей. В статье рассматриваются два аспекта, связанные с доступностью образовательных учреждений: прием учеников в школу и интеграция детей с трудностями в обучении, имеющих ограничения по здоровью. Результаты исследования демонстрируют, что высокие показатели качества обучения, благодаря которому многие католические школы попадают в рейтинг лучших учебных заведений Польши, достигаются за счет использования инструментов отбора учеников. Родительская плата за обучение определяет круг семей со средним уровнем доходов. Другим критерием при зачислении являются показатели индивидуальных успехов учеников, которые также рассматриваются как результат усилий родителей и социального окружения. Различные инструменты отбора учеников применяются в крупных центральных школах, которые предлагают востребованные образовательные программы, а также располагают возможностями для привлечения квалифицированных педагогов и организации дополнительных учебных и внеучебных занятий. Небольшие школы в районах и пригородах Варшавы по организационным

Татьяна Анатольевна Власова - к.философ.н., доцент, доцент кафедры социологии, Удмуртский государственный университет, Ижевск, Россия. Электронная почта: tavlasova@yandex.ru 
принципам не отличаются от государственных учебных заведений. Единственным механизмом, с помощью которого администрация школ может влиять на контингент учеников, является родительская плата за обучение. В то же время политика таких образовательных учреждений предусматривает создание принимающей среды для учеников, требующих индивидуального подхода. Идеология католических школ предполагает поддержку принципов инклюзивного образования. Тем не менее основные ресурсы образовательных учреждений направлены на достижение высоких образовательных результатов, а принципы инклюзии имеют вторичное значение.

Ключевые слова: социология образования, инклюзия, католические школы, образовательные барьеры

DOI: 10.17323/727-0634-2019-17-3-407-422

С начала 1990-х гг. в странах Центральной и Восточной Европы происходит трансформация образования. Реформы имеют различный характер, но общую тенденцию - появление учебных заведений, дополняющих сеть государственных школ. Большинство католических школ открылось в последние два десятилетия. Однако школы монашеских орденов (Назаретянки, орден Воскресения Иисуса) работали в течение всего социалистического периода, когда деятельность католических школ разрешалась только в рамках начального уровня образования.

Одним из условий работы католических школ в социалистический период был прием детей, которые имели сложности в освоении учебной программы или проблемы со здоровьем. В современной Польше частные школы ориентированы на образовательные запросы разных категорий учеников. Такая установка способствует развитию индивидуализированных образовательных стратегий. Это особенно актуально для создания дружественной социальной среды для тех детей, которые имеют трудности при обучении в общеобразовательных учебных заведениях. Однако плата за обучение в частной школе составляет от 600 до 1200 злотых в месяц при среднемесячной заработной плате 4000-5000 злотых. Дети из семей с низкими доходами могут обучаться в частных школах, только если в учебных заведениях есть программы финансовой помощи ученикам.

Значительная часть негосударственных частных школ в настоящее время представлена католическими учебными заведениями. От общего числа общеобразовательных учебных организаций на территории Польши государственные и негосударственные католические школы составляют около 6\% (данные предоставлены автору Управлением образования в Варшаве (Kuratorium Oświaty w Warszawie). В соответствии с положениями реформы образования, проведенной в Польше в 1999 г., установлено три уровня обучения: начальная школа (szkoła podstawowa) - шесть лет, гимназия (gimnazjum) - три года и лицей (liceum) - три года. В учебном заведении 
может реализовываться программа одного из уровней, а могут сочетаться два (начальная школа и гимназия, гимназия и лицей) или все три уровня (Мареш 2001:38-39).

Принципы организации обучения в католических школах зависят от особенностей устава учебного заведения. Часть католических школ относится к братским или сестринским монашеским орденам. Другие школы были открыты при приходах. Они теснее связаны с интересами родителей, которые в этом случае являются прихожанами. Третья категория школ появилась в результате инициативы общественных организаций. Примером школ такого рода являются учебные заведения, работающие под эгидой общественной организации «Альянс семей», возникшей на основе клубов католической интеллигенции, которые начали создаваться еще в пятидесятые годы XX в. (Грыз 2016:32-34). Под эгидой «Альянса семей» в Варшаве в последние двадцать лет было открыто несколько школ, автономных учебных учреждений, связанных в единую сеть. Эти школы в большей степени связаны с общественными движениями, нежели собственно с религиозными институтами.

В настоящей статье представлен анализ системы частных католических школ в Польше как один из вариантов постсоциалистической трансформации сферы образования в Центральной и Восточной Европе. Во всех бывших социалистических странах появились негосударственные учебные заведения, но в Польше сектор частного образования развивался особенно динамично благодаря большому количеству католических школ. Католические ценности рассматриваются здесь как замена социалистической идеологии. Подходы к образованию и воспитанию в католических школах позиционируются как отказ от прежней «уравниловки» в пользу индивидуализации учебного процесса. Однако принципы его организации не позволяют реализовать инклюзивные стратегии в полной мере. Пример католических школ демонстрирует основные противоречия формирования инклюзивной культуры в сфере школьного образования. В социологических исследованиях использовалась концепция интеграционного замыкания, которая рассматривается в первом разделе статьи. Второй раздел посвящен описанию селективных практик в современных католических школах. Несмотря на процедуры отбора учеников, католические школы демонстрируют установку на внедрение инклюзивной культуры. Степень и характер реализации инклюзивных тенденций оценивается в третьем разделе.

\section{Феномен интеграционного замыкания в католических школах}

Феномен академического успеха учеников католических школ впервые был описан Джеймсом Коулманом. Анализ статистических данных выявил высокие показатели результатов стандартизированных тестов учеников 
католических школ в Чикаго. Кроме того, в католических учебных заведениях количество отчисленных учеников между 10 и 12 классами было значительно меньше (3,4\%), чем в государственных школах (14,4\%). Указанное различие не могло быть связано с тем, что школы были частными, потому что в негосударственных нерелигиозных школах процент отчисления также высок - 11,9\% (Coleman 1988: 115).

Коулман склонен считать причиной академической успешности учеников католических школ проявление эффекта «интеграционного замыкания» в семьях. Интеграционное замыкание возникает при интенсивном вовлечении в воспитательный процесс членов религиозной общины. Так, в католических семьях родственники теснее общаются между собой, крепче связь поколений. Кроме того, взаимодействие католиков внутри приходской общины способствует формированию обширной сети знакомых. Если в обычной ситуации родители одноклассников знают друг друга только по школе, то родители-католики знакомы и вне школьного пространства. Поэтому такие родители контролируют не только собственных детей, но и любого ребенка, которого знают и в отношении которого чувствуют ответственность. Иными словами, обнаруживается согласованность норм поведения и санкций. В религиозных школах ученики, родители, учителя и администрация школ вовлекаются в общий круг нормативного регулирования. Пользуясь каналами внешкольного взаимодействия, персонал школы быстрее и эффективнее распространяет общие нормы (Coleman 1988: 117).

Критика концепции Коулмана касалась описанной им процедуры отбора учеников, которая характерна для негосударственных школ. Оппоненты отмечали, что отбор снижает риски, связанные с нарушением дисциплины (McPartland, McDill 1982). Но Коулман и его соавторы указывают, что частные некатолические школы имеют такие же проблемы с дисциплиной, как и государственные (Hoffer et al. 1985: 77). Положительный эффект католической школы тем более очевиден, чем менее благоприятна ситуация, в которой ученик находится вне школы. Так, католические школы в США имеют максимальный положительный эффект для учеников из семей с низким социально-экономическим статусом или с низким первоначальным уровнем успешности. Отстающие дети в католической школе перестают быть заложниками плохих оценок и предвзятого отношения, в этих школах меньше проявления расовой и этнической сегрегации.

Состояние публичного и частного секторов школьного образования в современном Чикаго, где концентрируется наибольшее количество католических школ США, является результатом унификации школьного образования. Это способствовало стиранию различий между католическими и государственными школами. Но, когда в конце 2000-х гг. сократился объем финансирования школ, именно католические школы вынуждены были закрыться, так как родители больше не могли платить за обучение 
детей. Эти изменения поставили католические школы в невыгодное положение (Hallinan, Kubitschek 2012:4). Они стали принимать больше учеников, не являющихся католиками, детей с трудностями в обучении и детей с особенностями здоровья. В отсутствие процедур отбора успешность учеников старших классов стала страдать.

Таким образом, в США католические школы оказалась наиболее успешными в рамках негосударственного образовательного сектора на определенном этапе, но, когда они столкнулись с проблемой снижения количества учеников и с уменьшением финансирования, они также испытали снижение эффективности образовательного процесса (Mulvey et al. 2010:21). Власти городских округов США принимали решения в пользу поддержки католических школ на том основании, что многие из них располагались в неблагополучных городских кварталах и принимали детей из семей расовых и этнических меньшинств, а также детей с трудностями в обучении. Но чаще происходило изменение статуса школ, из частных они становились государственными. В помещениях католической школы открывались новые классы, хотя сохранялись некоторые элементы религиозного убранства или учебные предметы.

Масштабные исследования в США опирались на длительную традицию социологического изучения школ. За два последних десятилетия появилась возможность обобщить образовательные результаты, достигнутые и польскими католическими школами. Часть исследований носила общий, описательный характер (Мaj 2002; Cichosz 2013), и позволили сформулировать специфическую роль католических школ в негосударственном секторе среднего образования в Польше. Католические школы могут оперативно реагировать на семейные потребности, на растущее желание родителей обеспечить безопасность детям и предложить программу воспитания в русле католических ценностей (Smak 2014:27). Превознесение значения индивидуальных интересов (в духе христианского персонализма) над идеологией конкурентоспособности и работа на результат привлекают многих польских родителей, ориентированных на поиск подобной образовательной модели.

\section{Организация исследования: проблема доступа в пространство образовательных учреждений}

Представленное исследование основывается на материалах 24 качественных полуструктурированных интервью, которые собраны автором в декабре 2015 - апреле 2016 гг. Основной массив данных из учебных заведений составили интервью с директорами и завучами католических школ в Варшаве и ее пригородах (Легионово, Зомбки, Кобылце, Юзефув), одно интервью проведено в Гданьске. Исследование фокусировалось на социальных условиях, способствующих реализации индивидуальных стратегий обучения. 
Выбор качественной методологии связан с высокой степенью закрытости учебных заведений, особенно для иностранного исследователя. Школы были в разной степени доступны для изучения. Директора школ, связанных с монашескими орденами, реже соглашались на интервью. Наиболее открытыми оказались школы «Альянса семей», в которых и учителя, и представители администрации легко шли на контакт. Открытость этих школ, вероятно, связана со сложившимися практиками представления результатов их деятельности в публичном пространстве.

В Варшаве и ближайших пригородах располагается около 40 католических школ. Запрос на участие в исследовании был направлен во все школы. Согласие получено от директоров 19 учебных заведений. В трех школах, с администрацией которых удалось наладить дружественные отношения благодаря каналам неформального знакомства, директора предоставили возможность провести интервью с учителями. В ходе подготовки интервью, для чего требовалось несколько дней, проводилось неформализованное наблюдение, объектом которого были взаимодействия учителей и учеников в католических школах.

\section{Семья выбирает школу, а школа выбирает ученика}

Высокие показатели качества обучения в католических школах Польши фиксируются с момента их появления. Значительная часть школ, вошедших в список 500 лучших учебных заведений Польши,- католические. Как уже упоминалось, доля католических школ среди учебных заведений среднего образования составляет $6 \%$. При этом доля католических школ, вошедших в число лучших, составляет $40 \%$ (Smak 2014:21). Основой для составления рейтинга служили баллы выпускных экзаменов, которые проводятся по окончании каждого уровня обучения (начальная школа, гимназия, лицей).

Католические школы ориентированы на различные категории городских семей. В классических работах о воспроизводстве социального неравенства анализировались различные формы педагогического отбора (Бурдье, Пассрон 2007). Имеет место двунаправленный процесс: родители выбирают школу, дающую их детям определенные образовательные возможности, в то же время школы применяют процедуры селекции подходящих учеников (Jennings 2010: 233).

В Польше сохранилась система закрепления за школами детей, живущих в близлежащих районах. Но эта система не является жесткой: ребенка могут принять в любую школу. Семья имеет достаточно широкий выбор из нескольких государственных и частных школ, особенно если живет в центре Варшавы. Строгие рекомендации о правилах приема обязательны для государственных учебных учреждений. Поскольку частные школы дополняют сеть государственных школ, постольку они, обладая относительной автономией, могут вводить собственные критерии отбора. Например, набирать 
только мальчиков или девочек, если школа относится к женскому или мужскому монашескому ордену. Вопрос об обязательной принадлежности к католическому приходу решается по-своему разными школами. Требование обязательного католического вероисповедания предъявляется в школах, относящихся к «Альянсу семей». Но в целом, с одной стороны, из-за уменьшения количества детей в современных польских семьях, школы снижают требования к поступающим. С другой, плата за обучение, которая установлена в частных школах, сама по себе является фильтром, отсекающим семьи с низким уровнем дохода. При этом администрация имеет право отказать в зачислении ученика под тем или иным предлогом, руководствуясь положением о том, что у семьи всегда есть альтернатива в виде государственной школы, куда ребенка должны принять в обязательном порядке.

Критерием высокой позиции в национальном рейтинге для школы (частной или государственной) служат баллы, полученные выпускниками на итоговых экзаменах. Католические школы в Польше реализуют специфические целеориентированные маркетинговые стратегии, чтобы привлечь наиболее подходящих учеников. В этом процессе демонстрируются сильные стороны школы, создается логотип, который используется для внутреннего оформления, одежды (обычно ученики носят школьную форму), предметов школьного обихода. При этом информационные материалы и содержание сайта школы часто рассчитаны на родителей с высоким уровнем образования и доходов и таким образом происходит исключение нежелательных малообеспеченных семей. Эти действия школ напоминают маркетинговые приемы продвижения бренда.

При наборе в школу администрация использует различные формы управления контингентом поступающих в зависимости от статуса школы и от уровня обучения, на который принимается ученик. Строгие процедуры отбора используют крупные учебные заведения, располагающиеся в дорогих районах Варшавы. Они известны как престижные школы, предлагают востребованные образовательные программы двуязычного (польский и английский) обучения. Другая категория школ - это небольшие школы в удаленных районах Варшавы или в пригородах. Они ориентированы на запросы семей, живущих там. Такие учебные заведения отличаются от государственных школ прежде всего ориентированностью на запросы «клиентов» - семьи (длительное пребывание ребенка в школе, дополнительные занятия) и относительной финансовой автономией, основанной на средствах, полученных от родителей.

Согласно интервью, школы второй категории (менее престижные) готовы принять любого ученика. Родителям достаточно подать заявление и пройти собеседование (Инт. 4, 8, 9, 19, 21). Набор в такие учебные заведения строится по следующей схеме: родители узнают основную информацию о школе на сайте учебного заведения или во время специально организованной встречи, затем заполняют документы. На следующем 
этапе назначается собеседование, присутствие на котором будущего ученика зависит от его возраста. Если речь идет о приеме в начальные классы, то собеседование проводится только с родителями. При поступлении в гимназию или лицей кандидат должен выразить личное согласие с католическим характером обучения и воспитания в школе. На основании собеседования ученики зачисляются в учебное заведение.

Престижные школы со сложившейся репутацией в дополнение к собеседованию используют процедуры, позволяющие отсеять кандидатов, набирающих низкие баллы на предварительных испытаниях. В таких школах при наборе в начальные классы отбираются скорее «подходящие» семьи: в ходе собеседования родителям задают вопросы о вероисповедании членов семьи, о месте работы, об их уровне образования и доходов. Причем значение имеет не один из перечисленных факторов, а их сочетание. Достигается согласие о том, что родители ждут от учебного заведения и что оно может предоставить семье и ребенку. Психологическая и интеллектуальная готовность детей к обучению может оцениваться будущим учителем или психологом. Некоторые школы используют практику пробного дня. В учебных заведениях «Альянса семей» предлагается провести день или два, участвуя в мастер-классах. В эти дни дети, поступающие в первый класс, участвуют в играх, конкурсах или мастерят игрушки под наблюдением учителей начальных классов и психологов. За действия разного типа ребенку начисляются баллы, которые оценивают уровень умственного и эмоционального развития, готовность сотрудничать с ровесниками и взрослыми, способность выполнять различные задания и умение использовать учебные предметы. На основе суммы набранных ребенком баллов происходит зачисление.

В некоторых школах пробный день предшествует собеседованию и, по словам одного из директоров, его результаты обсуждаются с родителями (Инт. 10). В другой школе, где также используется практика мастер-классов, их результаты известны только представителям администрации, так как они проводились после собеседования. В этом случае родители узнавали только о положительном или отрицательном решении о зачислении ребенка (Инт. 2). Эксплицитная цель отбора в начальную школу состоит в том, чтобы сформировать классы из учеников, успешно справляющихся со школьной программой. Но имплицитно проводится отбор семей соответствующей социальной категории. В третьей школе «Альянса семей» предлагается иной способ решения той же проблемы при наборе в один из первых классов детей, не достигших семилетнего возраста. Этот класс имеет собственную программу. В другой первый класс параллели набирают детей постарше. Однако в этой школе имеются более строгие требования к членству семей в Клубе католической интеллигенции и принадлежности к приходской общине. Таким образом, школы используют различные основания для отсева «неподходящих» кандидатов при формировании контингента учеников. 
Еще одним фильтром является академическая успеваемость. Оценки за предыдущие годы обучения имеют значение при поступлении в гимназию и лицей. Директора и учителя школ высказывали различное отношение к отметкам как показателю знаний учеников, вплоть до крайне скептического (Инт. 10). Тем не менее при приеме в гимназию и лицей кандидаты обычно предоставляют сертификат об оценках и результаты финальных экзаменов по математике, польскому и иностранному языкам. В двух интервью директора отмечали, что при поступлении требуется также характеристика из прежней школы. Многие школы, где есть уровень гимназии и лицея, предлагают кандидатам сдать внутренние экзамены по основным предметам несмотря на то, что поступающие предоставляют табель с оценками за прошлый год и результаты экзаменов.

В Варшаве семья располагает достаточно широкими возможностями выбора учебного заведения. В других городах Польши престижные католические школы имеют очень высокий статус, и процедура селекции подходящих учеников может быть еще более строгой. Например, контингент учащихся школы в Гданьске формируется задолго до того, как дети достигают школьного возраста: «чтобы попасть в нашу школу, нужно за три года до этого записаться» (Инт. 15).

Таким образом, степень селективности при наборе в школу прямо связана с конкуренцией учебных заведений. Престижные учебные заведения, которые располагают ресурсами, отсутствующими у остальных государственных или частных общеобразовательных школ, широко используют различные инструменты отбора наиболее подготовленных учеников. В католические школы приходят дети, которые обеспечены финансовым, социальным и культурным капиталом семей, принадлежащих среднему классу польского общества. С другой стороны, районные католические школы предлагают условия обучения, почти не отличающиеся от государственных учебных заведений. Чтобы привлечь учеников, они не предъявляют высоких требований к уровню подготовки. Конкурируя за учеников, районные школы пытаются создать благоприятную образовательную среду для тех из них, кто испытывает сложности в обычном школьном окружении.

\section{Способы поддержки нетипичных учеников}

Католические школы позиционируют себя как учебные заведения с поддерживающими установками и опирающиеся на идеологические принципы солидарности и взаимной помощи. Рассмотрим различные практики, которые директора и сотрудники школ представляли как реализацию принципа доступности учебных заведений. Некоторые католические школы Варшавы, особенно учебные заведения монашеских орденов, имеют пансион для мальчиков или девочек. Обычно в этих школах существует гендерная сегрегация. Подростки из небольших городков и деревень после окончания 
начальной школы приезжают учиться в Варшаву в гимназии или лицее. Обучение с круглосуточным пребыванием дает возможность получить качественное образование детям из глубинки (Инт. 13). Такая форма устройства детей в школе позволяет учиться в католических школах детям из семей иностранцев, еще недостаточно владеющих польским языком. Как правило, родителям детей, плохо знающим польский язык, администрация государственных школ прямо предлагает частную школу в качестве учебного заведения, где ученику помогут справиться с языковым барьером.

Уставные документы многих католических школ подчеркивают важность инклюзии в отношении детей с ограниченными возможностями здоровья и трудностями в учебе. Однако реальные условия обучения детей редко дают возможность в полной мере внедрить инклюзивные практики в образование. Отметим, что работа с детьми, имеющими трудности в обучении и проблемы с поведением, была условием сохранения того небольшого числа католических школ, которые действовали в социалистический период истории Польши. В настоящее время реализация инклюзивных программ зависит от внутренних принципов администрации школы. В трех интервью директора представляли следующую позицию: учебное заведение нацелено на достижение высоких образовательных результатов, поэтому политика школы направлена на прием успешных и амбициозных учеников, а сегрегация, с их точки зрения, оправдана:

Если речь идет о проблемах в обучении, то мы являемся школой для молодежи, которая хочет учиться. $<\ldots .>$ Мы не хотим смешивать в школе амбициозную молодёжь с молодежью с проблемами. Потому что тогда мы не сможем помочь ни тем - хорошим, ни другим (Инт. 18).

В Польше распространена практика так называемых «интеграционных» школ, которые являются не инклюзивными, а коррекционными. Директора наиболее престижных католических школ указывали, что в интеграционных школах детям легче «справляться с их трудностями» (Инт. 10, 19).

Обычной можно считать установку на прием в католические школы детей с нетяжелыми формами инвалидности. Директора большинства католических школ отмечали, что учебные учреждения могут принимать лишь тех детей, которые не имеют трудностей с передвижением, хотя в коридорах и классах можно увидеть детей с легкой формой ДЦП, встречаются дети со слуховым аппаратом. Информанты говорили о примерах обучения детей с синдромом Аспергера, а также с учебными дисфункциями (дислексией и дисграфией). Во всех этих случаях достигалось соглашение между персоналом школы и родителями о том, в какой форме будет осуществляться их сотрудничество. Как правило, предполагалось, что родители не должны ожидать высоких образовательных результатов, устанавливалась договоренность о разделении ответственности между педагогами и родителями. Заметим, что большинство государственных и частных школ занимают здания, 
построенные 30-40 лет назад, а некоторые располагаются в довоенных. Часто встречается ситуация, когда в трех-, четырехэтажных зданиях нет лифта, ступеньки в лестничных пролетах достаточно крутые, кабинеты одного этажа располагаются на разных уровнях, преобладают узкие дверные проемы. Все это исключает перемещение в инвалидной коляске.

В интервью обычно разворачивалось повествование о тех случаях, когда присутствие ребенка в школе завершалось разочарованием:

Несколько лет назад была девочка <... , но оказалось, что учёба идёт трудно... И она перешла в интеграционную школу. Но мы принимаем таких детей, однако всегда разговариваем с родителями на тему, как они себе представляют [наше] сотрудничество (Инт. 11).

В целом, информанты принимали идеи инклюзии. Сложности в реализации инклюзивной образовательной политики они связывали с отсутствием средств на организацию доступной среды в школе и нехваткой специально подготовленных педагогов (Инт. 2, 5, 9, 11, 13, 15, 16, 21, 22 , $23,24)$. Но в ряде школ идеи инклюзии трансформируются в конкретные виды помощи ученикам. В этом случае информанты подчеркивали, что ресурсы школы направлены на создание поддерживающей среды, а индивидуальный подход к обучению рассматривается как способ решения проблем (Инт. 8). Директора указывали, что в условиях современной школы каждый ученик нуждается в особом подходе. Согласно рассказам директоров католических школ, именно в католических школах дети, в том числе имеющие дополнительные потребности по показателям здоровья, получают дополнительное внимание учителей (Инт. 20), с ними занимается психолог, при необходимости они получают помощь со стороны медицинского персонала (Инт. 4, 14, 17, 20). В одной из школ есть опыт привлечения волонтеров, которые сопровождают учеников с инвалидностью, либо дополнительно занимаются с неуспевающими (Инт. 14).

В качестве важной составляющей католического воспитания директора школ называли религиозное волонтерство. Хотя конкретные волонтерские программы описывались лишь в двух интервью (Инт. 11, 20), информация о волонтерских программах и акциях размещена на интернет-сайтах. В католических школах проходят благотворительные акции в помощь пожилым людям, людям с умственными заболеваниями. Некоторые волонтерские мероприятия имеют масштабный характер, в частности, в одно из воскресений октября проводится сбор средств в помощь нуждающимся под эгидой фонда Иоанна Павла Второго.

\section{Заключение}

Католические учебные заведения в Польше играют важную роль в сфере образования. Предоставляя возможность получить качественное 
образование в условиях, ориентированных на запросы некоторых семей, католические школы наиболее востребованы теми родителями и учениками, которые, с одной стороны, нуждаются в индивидуализированном обучении, а с другой - имеют средства на оплату обучения.

Социологические исследования успешности учеников католических школ в США позволяют утверждать, что наиболее благоприятный эффект обеспечивался ученикам, которые испытывали трудности при обучении в общеобразовательных учебных заведениях, для детей с инвалидностью, а также для детей, принадлежавших к расовым и этническим менышинствам. Однако в Польше католические школы обладают ограниченными ресурсами и не могут в полной мере реализовать программу инклюзивного обучения.

В католических учебных заведения Польши широко используют инструменты селекции учеников. Кроме платы, которая предполагает, что семья имеет уровень доходов не ниже среднего, персонал школы учитывает учебные показатели. Католическое вероисповедание служит фактором интеграции семьи в религиозную общину, поэтому оно также является важным при приеме ребенка в школу. Позиция администрации по отношению к процедурам отбора учеников зависит от статуса школы. В меньшей степени селекция используется в небольших районных школах, когда количество потенциальных учеников невелико. Напротив, отбор учеников является более строгим в крупных центральных учебных заведениях со сложившейся репутацией. Противоречие реализации миссии католических школ по индивидуальному подходу к ребенку проявляется на примере барьеров при приеме учеников с проблемами в обучении и поведении, а также детей с инвалидностью.

Представленное исследование развивает дискуссии о различных направлениях постсоциалистических трансформаций в странах Восточной Европы. Пример Польши демонстрирует результаты такой траектории развития, которая ориентируется на расширение частного сектора школьного образования. В постсоветских странах (Прибалтике, Украине, России) общеобразовательные учебные заведения остаются преимущественно государственными. Собранный материал позволяет оценить практики отбора учеников с точки зрения организационных условий в католических школах.

\section{Выражения благодарности}

Исследование проводилось в рамках стажировки по программе академического обмена Erasmus Mundus Aurora.

\section{Описание полевых данных}

Интервью 1. Мужчина, 46 лет, директор интерната при католическом лицее, Варшава. 
Интервью 2. Женщина, 39 лет, директор начальной школы «Альянса семей», Варшава.

Интервью 3. Женщина, 32 года, учитель математики, гимназия и лицей сестринского ордена, Варшава.

Интервью 4. Женщина, 52 года, директор католической начальной школы, Варшава.

Интервью 5. Мужчина, 49 лет, директор католической начальной школы и гимназии, Варшава.

Интервью 6. Женщина, 51 год, директор католического лицея, Варшава.

Интервью 7. Женщина, 57 лет, учитель русского языка в католическом лицее, Варшава.

Интервью 8. Женщина, 54 года, директор католического лицея, Варшава.

Интервью 9. Женщина, 29 лет, завуч католической школы, Юзефув.

Интервью 10. Мужчина, 34 года, директор католической школы, Варшава.

Интервью 11. Женщина, 36 лет, завуч гимназии Альянс семей, Варшава.

Интервью 12. Женщина, 64 года, завуч, гимназия и лицей сестринского ордена, Варшава.

Интервью 13. Женщина, 43 года, директор, гимназия и лицей сестринского ордена, Варшава.

Интервью 14. Женщина, 57 лет, директор католической школы, Зомбки.

Интервью 15. Мужчина, 39 лет, директор католической школы, Гданьск.

Интервью 16. Женщина, 37 лет, директор начальной школы, Варшава.

Интервью 17. Женщина, 53 года, директор начальной школы «Альянса семей», Варшава.

Интервью 18. Мужчина, 38 лет, директор католической гимназии, Легионово.

Интервью19. Мужчина,62 года, директор лицея «Альянса семей», Варшава.

Интервью 20. Женщина, 36 лет, завуч католической начальной школы, Варшава.

Интервью 21. Женщина, 47 лет, директор католической начальной школы, Кобылце.

Интервью 22. Мужчина, 27 лет, завуч христианской начальной школы, Варшава.

Интервью 23. Женщина, 48 лет, завуч начальной школы и гимназии «Альянса семей», Варшава.

Интервью 24. Женщина, 50 лет, завуч католической начальной школы, Варшава.

\section{Список источников}

Бурдье П., Пассрон Ж.-К. (2007) Воспроизводство: элементы теории системь образования. М.: Просвещение.

Грыз Р. (2016) Римско-католическая церковь в Польской Народной Республике (1944/45-1989): формы сосуществования с режимом и роль идейной оппозиции. Государство. Религия. Церковь в России и за рубежом, 34 (3): 11-43.

Мареш Т. (2011) Система образования в современной Польше. Проблемы современного образования, (5):38-45.

Cichosz W. (2013) Mozliwosci dialogu wychowania chrzescijanskiego ze wspolczesna educacja Polska. Krakow: Pelplin. 
Coleman J. S. (1988) Social Capital in the Creation of Human Capital. American Journal of Sociology, (94): 95-120.

Hallinan M., Kubitschek W.N. (2012) A Comparison of Academic Achievement and Adherence to the Common School Ideal in Public Schools. Sociology of Education, (85): 1-22.

Hoffer T., Greeley A. M., Coleman J. S. (1985) Achievement Growth in Public and Catholic Schools. Sociology of Education, (58): 74-97.

Jennings J. L. (2010) School choice or Schools' Choice? Managing in an Era of Accountability. Sociology of Education, 83 (3):227-247.

Maj A. (2002) Szkolnictwo katolickie w III RP (198--2001). Wazszawa: Wydawnictwo Uniwersytetu Waszawskiego.

McPartland J.M., McDill E.L. (1982) Control and Differentiation in the Structure of American Education. Sociology of Education, 55 (2): 77-88.

Mulvey J. D., Maloney A. T., Cooper B. S. (2010) Blurring the lines: Charter, Public, Private and religious Schools Coming together. Charlotte: Information Age Publishing.

Smak M. (2014) Czynniki warunkujące zainteresowanie szkołami katolickimi. Opuscula sociologica, (4): 17-29. 
Tatiana Vlasova

\section{INCLUSION AND SELECTION IN CATHOLIC SCHOOLS IN POLAND}

Post-socialistic transformations of the education systems in Central and Eastern Europe were different. While in Russia the major part of secondary education institutions remains public, in Poland a segment of private schools was formed at the same time. Private educational institutions are focused on individual learning strategies. This pattern is most typical for Catholic schools. The purpose of the article is to evaluate the inclusive attitudes of Catholic schools in Poland. The qualitative sociological study is based on a range of semi-structured interviews with principals and teachers. The data allow a description of both the selection procedures of students and the way disabled children are integrated. The article deals with two aspects related to the accessibility of educational institutions: enrollment students to school and the integration of children with learning difficulties with disability. The findings of the research demonstrate that the high education scores due to Catholic schools enter into the chart of the best educational institutions in Poland. This process is achieved by using selective tools. Parental tuition fee is available for middle class families. Another reason for students' enrollment is academic success, which is also confirmed by final scores which depend on influence of parents and the social environment. Various students selection tools are used in large magnet schools which offer required educational programs. As well as institutional policy of catholic schools provides the supportive environment for disabled students. The ideology of Catholic schools is based on adoption of the concepts of inclusive education. It means the promotion of the ideas of solidarity and mutual assistance. The volunteer movement is developing too. Nevertheless, the main resources of schools are focused on achieving high educational results and the attitudes toward inclusiveness are less important. The success of students with difficulties in a Catholic school depends on family resources.

Keywords: sociology of education, inclusion, catholic schools, educational barriers

DOI: $10.17323 / 727-0634-2019-17-3-407-422$

\section{References}

Bourdieu P., Passeron J-C. (2007) Vosproizvodstvo: elementy teorii sistemy obrazovaniya [Reproduction in Education, Society and Culture]. Moscow: Prosveshchenie.

Cichosz W. (2013) Mozliwosci dialogu wychowania chrzescijanskiego ze wspolczesna educacja Polska. Krakow: Pelplin.

Tatiana Vlasova - Kandidat nauk (PhD) in Philosophy, Assistant Professor at the Department of Sociology, Udmurt State University, Izhevsk, Russian Federation. Email: tavlasova@yandex.ru 
Coleman J. S. (1988) Social Capital in the Creation of Human Capital. American Journal of Sociology, (94): 95-120.

Gryz R. (2016) Rimsko-katolicheskaja cerkov' v Pol'skoj Narodnoj Respublike (1944/45-1989): formy sosushhestvovanija s rezhimom i rol' idejnoj oppozicii. [Catholic Church in the People's Republic of Poland (1944/45-1989): Forms of Co-Existence with the Regime and the Role of Ideological Opposition]. Gosudarstvo. Religiya. Tserkov v Rossii Iza rubezhom [State. Religion. Church in Russia and Abroad], 34 (3): 11-43.

Hallinan M., Kubitschek W.N. (2012) A Comparison of Academic Achievement and Adherence to the Common School Ideal in Public Schools. Sociology of Education, (85): 1-22.

Hoffer T., Greeley A. M., Coleman J. S. (1985) Achievement Growth in Public and Catholic Schools. Sociology of Education, (58): 74-97.

Jennings J.L. (2010) School Choice or Schools' Choice? Managing in an Era of Accountability. Sociology of Education, 83 (3): 227-247.

Maj A. (2002) Szkolnictwo katolickie w III RP (1989-2001). Wazszawa: Wydawnictwo Uniwersytetu Waszawskiego.

Maresh T. (2011) Sistema obrazovaniya v sovremennoy Polshe [Education System in Modern Poland]. Problemy sovremennogo obrazovaniya [Problems of modern education], (5):38-45.

McPartland J.M., McDill E.L. (1982) Control and Differentiation in the Structure of American Education. Sociology of Education, 55 (2): 77-88.

Mulvey J. D., Maloney A. T., Cooper B. S. (2010) Blurring the Lines: Charter, Public, Private and Religious Schools Coming Together. Charlotte: Information Age Publishing.

Smak M. (2014) Czynniki warunkujące zainteresowanie szkołami katolickimi. Opuscula sociologica, (4): 17-29. 